\title{
Lenguas indígenas en los tribunales de América Latina: intérpretes, mediación, justicia (siglos XVI-XXI)
}

\author{
C CAROLINE CUNILL Y LUIS MIGUEL GLAVE \\ T E S T I N O, C O O R D S \\ Bogotá: Instituto Colombiano de Antropología e Historia. \\ 2019 | ISBN: 978-958-8852-75-1 | 348 pp.
}

DOI: https://doi.org/ 10.22380/20274688.1180

RENÁN SILVA

Investigador titular del Centro de Investigaciones en Historia de la Universidad Externado de Colombia

工 as lenguas indigenas en los tribunales de América Latina: intérpretes, mediaSe trata de nueve textos, organizados en tres grandes bloques, que cubren, en la medida en que es posible hacerlo, una variedad de regiones y situaciones que se encuentran cuando se estudia el tema de la relación entre las sociedades indígenas "americanas" y el nuevo orden administrativo impuesto por la monarquía castellana después de I500, aproximadamente, lo que supuso la puesta en contacto de sociedades con lenguas - hay que decirlo en plural- diferentes de las del conquistador. Ello le otorgó una gran centralidad al trabajo de los intérpretes y hace tan valioso el estudio de su papel y trayectorias, sin que haya necesidad, claro, de afirmar de forma tan rotunda que las trayectorias de los intérpretes "permiten esclarecer cómo funcionaba la justicia colonial" (67), según se lee en el texto — por lo demás excelente- de Yannanakis, o exagerar su 
poder e influencia en esa sociedad ${ }^{`}$. Quisiera mencionar las razones principales que me conducen a la afirmación de que se trata de un libro importante de leer — dejo de lado la buena presentación del volumen y del material gráfico que lo acompaña y menciono que todos sus autores son especialistas competentes en la materia de la que se ocupan-.

En primer lugar, hay que mencionar el tema, que desde luego tiene antecedentes, pero que aquí aparece enriquecido, pues aunque el asunto de los intérpretes había sido estudiado en el pasado y aparece mencionado de manera repetida en la documentación de archivo, su tratamiento detallado aún esperaba. Además, el libro pone su foco principal en un aspecto antes poco considerado: el del papel de los intérpretes de las lenguas indígenas (fueran estos indígenas, mestizos, criollos o españoles) en el campo de la justicia, del orden administrativo y de la ley ${ }^{2}$, y esa atención común de todos los autores al tema concreto y a algunas de sus dimensiones de análisis le otorga una gran unidad al volumen.

Por fuera de hacer visibles las relaciones complejas entre traducir e interpretar, el libro potencia la idea, por mucho tiempo abandonada, de la importancia del derecho y las normas jurídicas en las sociedades de "América colonial"; todos los textos muestran que la llamada "sociedad colonial" era una sociedad de leyes, garantías y protecciones, no en el sentido de la sociedad de hoy, sino bajo la forma precisa que la función de "dispensar justicia" adquiere en una sociedad monárquica de órdenes, como varios de los textos lo dicen explícitamente y todos lo suponen por el tratamiento mismo que hacen del objeto sobre el que investigan, y ello bien sea en los primeros años de la ocupación o en épocas siguientes en las cuales una organización administrativa y legal comenzaba a estabilizarse.

El punto es importante y resulta ser un paso más en el camino de crítica de la visión liberal del siglo xix que afirmaba que se trataba de una sociedad sometida al "despotismo de las autoridades", una visión que aún persiste y que impide captar la importancia del elemento jurídico desde temprano en estas sociedades. Así, el derecho, una importante creación de la vida social europea, se convirtió en un elemento incorporado, apropiado y enriquecido por su práctica en el Nuevo Mundo y asimismo en las sociedades que lo prolongarán en los siglos XIX-XXI.

I Véase, por ejemplo, el trabajo de Gamboa, quien califica al intérprete que estudia como "personaje con mucha influencia en la Real Audiencia y en la sociedad santafereña del siglo XVI” (II5), lo que no se infiere de manera tan concluyente de su análisis.

2 Véanse, por ejemplo, pp. 4I-43, por fuera de la Introducción. 
Esa revaloración del papel de los tribunales y de la justicia resulta acorde con la idea que recorre los textos, y que se impone como una conclusión al lector, acerca del papel activo del intérprete en la conformación de una cultura legal híbrida (I4). Sin embargo, como bien lo sabemos, las relaciones entre derecho y sociedad, en el plano del ejercicio de la justicia y de sus instituciones, iba mucho más allá del mundo de los intérpretes.

En segundo lugar, debe mencionarse que el libro aborda aspectos distintivos de la cultura, como son la lengua y el derecho, en el marco mismo de las viejas y de las nuevas estructuras sociales, apoyándose en el examen de fuentes que son clásicas en el campo de la historia social y que a veces una parte de los llamados "estudios culturales" ha tendido a dejar de lado. Desde su propio ángulo, los textos que se presentan abordan aspectos sustanciales de la vida de la sociedad (étnico-raciales, de parentesco, de relaciones de trabajo y de propiedad, de vida comunitaria, entre otros), poniendo de presente que no hay formas de separación o de exterioridad entre sociedad y cultura, sino dimensiones de la actividad humana que deben ser consideradas en su diferencia y en su relación.

Hay una rica historia social que recorre la obra, ilustrando muy bien el tipo de sociedades que se está considerando y que incluso invitaría a volver a reflexionar sobre la propia idea de "sociedad colonial", en el sentido habitual de la expresión. Me refiero a que la obra muestra en casi todos sus textos la riqueza de los sistemas de estratificación social de ese mundo en formación y la manera compleja como se organizan sus jerarquías sociales, cruzadas por elementos étnicos, de riqueza, de cultura, de parentesco, de trayectoria, que se combinan para dar lugar a un mundo social que es, también desde el punto de vista de las sociedades indígenas, "comunitario", pero al mismo tiempo heterogéneo, múltiple en sus distinciones, rico en procesos de individuación y en historias de vida personal y que involucra, desde el propio siglo xvI, formas de separación social que incluyen elementos de riqueza patrimonial y distinción cultural. De tal forma, el lector puede tener al final una imagen más rica y variada que la que a veces de manera explícita afirman algunos de los autores de la propia obra, cuando en muchas de sus páginas insisten en la existencia de un mundo estrictamente dividido entre una "élite" que concentra todo poder y riqueza y una masa aplastante de "indígenas". 
Esa perspectiva de historia social que menciono como virtud notable está conectada en la obra, y es el cuarto elemento que quiero resaltar, con un examen abundante de fuentes - que se mencionan con todo rigor- y con un tratamiento de método afortunado que combina las escalas de análisis y que recurre con acierto al "estudio de caso" - en el sentido actual que los historiadores le dan a la expresión-. Ello permite mostrar la riqueza de los eventos locales y las formas singulares de apropiación del universo cultural impuesto por España, por parte de las sociedades indígenas, primero, y luego "mestizo-indígenas" y criollas, sin que ninguno de los textos trascienda de manera innecesaria sus definiciones espaciales y temporales y el contexto general de la monarquía - aunque habría que excluir de esta observación el Epílogo de la obra, que parece avanzar en otra dirección-.

Terminada la lectura del volumen, se debe reconocer que el lector sale enriquecido, con muchas preguntas sobre una realidad que poco se ha interrogado bajo el ángulo en que aquí se le interroga, y con nuevas inquietudes en términos de la interpretación que se ofrece. Es claro que se trata de una obra que muestra un importante camino recorrido, e indica muchas de las vías para continuar, en clave pasada o presente, trabajando sobre una cantera de investigación que no debe abandonarse. De manera brevísima, como lo imponen los términos de una reseña, quiero mencionar algunas observaciones críticas que desde luego no alteran la idea de que se trata de una obra notable.

Me parece, en primer lugar, que la obra no escapa siempre al anacronismo, y ello a pesar de las advertencias explícitas que se encuentran en el texto, por ejemplo en las páginas de Jorge Gamboa, cuando menciona los abusos frecuentes que se hacen de la expresión "corrupción administrativa" y la incapacidad de integrar ese fenómeno a la explicación del funcionamiento "normal” de las estructuras sociales y políticas singulares de aquellas sociedades.

En la obra parece haber en ocasiones cierta falta de sensibilidad para captar la especificidad temporal de las sociedades que se estudian, lo que se pone de presente, por ejemplo, cuando se quiere caracterizar la "actividad política" de los intérpretes y se habla de "intereses", de "intenciones políticas", de "servilismo político" de algunos de sus actores, o cuando se supone en cada una de las acciones de la Corona española y sus funcionarios una "intencionalidad" de legitimación, o bien cuando se habla de manera repetida del "Estado colonial"- o aun del "Estado neoinca", como en el texto de Glave-, sin que sepamos nunca a qué estructuras políticas particulares se hace referencia. Sobre todo, deja muchas dudas la aplicación del término de "Estado colonial" a los 
años más tempranos de la colonización — también se habla de "pacto colonial", sin mayores aclaraciones-, a un incipiente entable administrativo aún en sus primeras formas de organización.

Me parece que a este respecto circulan en la obra visiones alternas, que no son complementarias, sino más bien opuestas, de la sociedad y la política de esa particular formación social que se está configurando en los siglos XVI-XVIII, hecho visible en el recurso, por ejemplo, en uno de sus textos, a nociones como la de "monarquía compuesta", tal vez recogiendo la excelente idea de John Elliott, aunque en ese mismo texto se afirme la idea de una "sociedad colonial" en el más claro sentido del siglo xix. Ello además puede llegar a hacer inútil la idea de apropiación y de riqueza de los niveles locales en que se expresa la acción histórica y en la idea de creación de una "cultura híbrida local", al tiempo que no se arriba a ninguna conclusión a partir de los propios datos de historia social que recorren la obra, especialmente aquellos que ilustran las trayectorias de los “intérpretes y traductores" que son el centro del análisis.

Anacronismo y también algún pecadillo de rigor igualmente en el uso de la idea de "profesión", una compleja idea de la sociología, aplicada a los intérpretes sin ninguna especificación precisa (alguno de los autores llega incluso a hablar de su "profesionalidad"), al tiempo que algunas nociones mínimas básicas en la obra no reciben mayor aclaración: así, por ejemplo, las nociones de "lenguaje", "lengua" e "idioma", que a veces resultan ser puramente alternativas y simple asunto de vocabulario, o el recurso a expresiones enigmáticas como la de "operadores políticos", que el contexto de uso no logra esclarecer, o la más trivial de "escena", o aun la caracterización de los intérpretes con el vocablo indefinido de "personajes" (o "personajes interesantes", "personaje muy interesante" y otras expresiones similares).

Hay un aspecto en la obra que a veces puede resultar enojoso y es su constante autorreferencialidad, en la medida en que los autores, en un gran juego de espejos, se reenvían unos a otros, como si el problema que estudian no tuviera exterior, como si otras versiones, que deberían citarse, no existieran, lo que se expresa de inmediato en dos problemas: las lagunas de su bibliografía, por extensa que sea, y la ausencia en la obra de toda perspectiva comparativa, así fuera mínima, como si el asunto considerado constituyera una singularidad exclusiva del mundo americano y no una constante de muy diversos procesos de "ocupación y colonización" que han conocido las sociedades humanas. Lo anterior hace que resulte un asunto bastante familiar a los antropólogos: solamente menciono una experiencia histórica precisa en la que se plantearon de 
manera acusada los problemas de interpretación en torno a textos legales entre sociedades nativas, grupos de ocupación y presencia de la escritura como instancia que concreta la ley en el Occidente moderno.

Me refiero a la situación de los indígenas en Australia y Nueva Zelanda, estudiada de manera pertinente por el sociólogo del libro y la escritura Donald McKenzie. Esa falta de cualquier elemento comparativo y de exterioridad le da a la obra por momentos una especie de carácter de "programa” y hasta "manifiesto" de grupo, y a los autores parece uniformarlos a manera de disciplinados escolares, máxime si se tiene en cuenta que algunas obras importantes en el campo de los "mediadores culturales" no son incluidas en la bibliografía — para mencionar un solo caso: el ciclo de obras que Sergio Gruzinski y algunos de sus colaboradores propusieron hace pocos ańos sobre el tema, y que no merece ni una sola mención-.

Una sola palabra final sobre el Epílogo de la obra, que de manera manifiesta no constituye un análisis de historia, sino más bien una declaración de fidelidad a un autor — el profesor Bartolomé Clavero, gran estudioso de la historia del derecho-, junto con algunas observaciones conocidas que ponderan una de las formas de evolución actual del derecho, sin que el autor del texto le suponga a ese esquema siquiera un solo problema en su interpretación, lo que lo lleva a plantear proposiciones que habría que mirar por lo menos con prudencia, como aquella que caracteriza la lucha por la igualdad en el siglo xix y el horizonte de la ciudadanía como un simple "parapeto" — esa es la palabra que se utiliza- montado por liberales y republicanos en aquel siglo para escamotear las reivindicaciones de los demás grupos sociales, en particular de las comunidades indígenas. ¡Vaya descubrimiento!, por el cual se caracteriza la lucha en el siglo XIX — y luego- de muchos hombres y mujeres de letras de muy distintas posiciones sociales y niveles culturales como una simple coartada y como una forma de engaño para las mayorías, confundiendo los avatares y tropiezos de una larga lucha por conquistar un ideal con una simple máscara de dominio y poder, olvidando la injusticia que significa condenar a una época y a unos grupos sociales por no responder a unas realidades sociales e intelectuales que antes del siglo xx no existían ni como preguntas.

Hay que señalar de todas maneras que el "Epílogo", que repito no es un análisis histórico, es la forma extrema de manifestación de una tensión que de manera desigual recorre toda la obra, y que es característica de las difíciles relaciones que en las ciencias sociales sostiene la actitud militante y reivindicativa con la comprensión de una época en sus propios términos, lo que lleva muchas 
veces a proyectar sobre el pasado nuestros juicios políticos en el presente. Claro, son cuestiones mayores, imposibles de discutir en los términos de una reseña, y que, como señalé, no disminuyen la importancia de la obra, pero que me parece que no deben dejar de mencionarse.

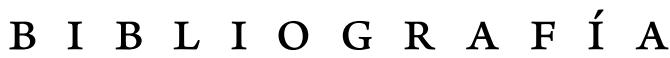

Mckenzie, D. F. "Cultura oral, alfabetización e imprenta en los primeros años de Nueva Zelandia”. Bibliografía y sociología de los textos. 1999. Madrid: AKAL, 2005, pp. 92-I40. 